\title{
Molecular insight of the possible inhibition mechanism of therapeutic cephalosporin derivatives against human glutathione reductase enzyme
}

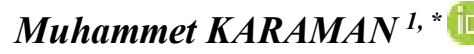 \\ ${ }^{1}$ Kilis 7 Arallk University, Faculty of Arts and Science, Department of Molecular Biology and Genetics, 79100, Kilis/ TURKEY
}

\begin{abstract}
Glutathione reductase is a key enzyme for glutathione metabolism. Inhibition of the enzyme activity related to various health problems. Therefore, determination of inhibitors of the enzyme and its possible inhibition mechanism are quite important. Some cephalosporins have exhibited potent inhibitory effect against human glutathione reductase (hGR). In order to understand the inhibition mechanism of the cephalosporins, we carried out molecular docking studies with Glide docking and Induced-fit Docking methods. Binding sites of hGR were predicted and the best suitable binding site of the drugs was identified with the Glide docking method. The binding affinity of the drugs was calculated with the induced-fit docking method. The best binding site of the drugs was detected as a part of the catalytic active site for Cefoperazone, Cefodizime, and Ceftazidime, dimerization site for Cefotaxime, Ceftriaxone, and Cefuroxime, and aromate binding site for Ceftizoxime. The Binding affinity of the Cefoperazone was calculated as $-10.643 \mathrm{kcal} / \mathrm{mol}$. The results have indicated that hGR enzyme would be inhibited with different mechanisms because of its several druggable sites. These findings would be helpful for designing new inhibitors for hGR enzyme and understanding of potential inhibition mechanism of its other known inhibitors.
\end{abstract}

\author{
Article info \\ History: \\ Received:08.10.2019 \\ Accepted:05.06.2020 \\ Keywords: \\ Cephalosporins, \\ Glutathione reductase, \\ Glide docking, \\ Induced-fit docking, \\ Inhibition mechanism.
}

\section{Introduction}

Antibiotics are chemical substances naturally produced by bacteria and plant as well as synthesis in the laboratory. The chemical substances exhibit antibacterial activity by killing or growth arresting of bacteria [1] through inhibition mechanisms of cell wall synthesis [2], cell membrane function [3], ribosome function [4], nucleic acid synthesis [5, 6] and folate metabolism [7]. Physical, chemical, microbiological, pharmacological and finally clinical properties of antibacterial agents depend on its chemical structure [8] and they can be classified as macrolides and lincosamides, quinolones, trimethoprim, tetracyclines, cephalosporins, penicillinase-resistant penicillins, narrow-spectrum penicillins and broad-spectrum penicillins according to the chemical structure.

Cephalosporins are derived from cephalosporin C which is a natural product of Cephalosporium acremonium [9]. The molecular structures of cephalosporins are closely related to penicillin with a $\beta$-lactam ring. They exhibit antibacterial activity by inhibiting bacterial cell wall synthesis like other antibiotics that have a $\beta$-lactam ring [10]. The cephalosporins can be classified in different ways. However, the most favourite classification is based on generation. The classification is made according to a general spectrum of the drugs' activity [11]. Firstgeneration cephalosporins are used for the treatment of infection caused by Gram-positive bacteria such as Streptococci and Staphylococci. But they have a relatively narrow spectrum of activity against them [12]. Second-generation cephalosporins have broader activity against the Gram-negative bacteria, unlike the first generation [11] and they also exhibit resistance to $\beta$-lactamase [13]. The activity of third-generation cephalosporins is improved against Gram-negative bacteria compared to the second-generation. In addition to this, fourth-generation cephalosporins have the broadest spectrum of activity against both Grampositive and Gram-negative bacteria. Finally, the fifthgeneration cephalosporins have enhanced activity against multidrug-resistant gram-positive cocci [11]. More than fifty cephalosporins have been discovered involving all generations since 1945 [14]. It is known that cefalosporins may cause side effects such as reversible thrombocytopenia, hemolytic anemia, neutropenia, interstitial nephritis or abnormal liver

\footnotetext{
*Corresponding author. Email address: mhmmtkaraman@gmail.com

http://dergipark.gov.tr/csj $\quad$ (C)2020 Faculty of Science, Sivas Cumhuriyet University
} 
function depending on using more than two weeks [10].

Glutathione (GSH) is an essential molecule in all mammalian cell and is the most abounded non-protein sulfhydryl group [15]. It has several critical cellular functions such as participating as a coenzyme in some enzymatic reactions, protection of the thiol moieties of proteins and low molecular weight compounds, detoxification of toxic compounds and also protecting against oxidative damage [16]. Glutathione reductase (GR) plays a key role in glutathione metabolism because it catalyzes the reduction of glutathione disulfide (GSSG) in the presence of NADPH [17]. Naturally, intracellular concentrations of glutathione change between 0.5 and $10 \mathrm{mM}$ in the mammalian cell [18] and the ratio of [GSH]/[GSSG] exceeds 100 in the resting cell. However, the reduced form of glutathione (GSH) is converted to oxidized form (GSSG) because of oxidative stress and therefore the ratio decreases in the cell [19]. In tissues, GSH concentration should be kept constant at the mentioned ratio above due to it is one of the most important components of the overall antioxidant defense system in the body. This flavin enzyme ensures the maintaining of high GSH and low GSSG levels. Therefore it prevents interrupting of glutathione-related functions in the cell [20]. Many researchers have investigated the effects of some antibiotics on GR enzyme activities in human erythrocyte as in vitro [21-23].

In the literature, there are many studies which detected the inhibitory effect of drugs against human glutathione reductase (hGR) enzyme. However, there is not much information about their inhibition mechanisms on hGR enzyme. Our study shed some light on the explanation of the mechanisms using computational methods. It has identified that cefoperazone, cefodizime, cefotaxime, ceftazidime, ceftizoxime, ceftriaxone and cefuroxime are the potent inhibitors of hGR at previously reported in vitro studies $[21,22,24]$. In order to explore the possible inhibition mechanism of the drugs against hGR enzyme, we performed the Glide docking and the induced fit docking (IFD) studies with these drugs against the three-dimensional (3D) structure of the enzyme.

\section{Material and Method}

\subsection{Protein target selection and processing}

The X-ray crystal structure of hGR enzyme (PDB code: 3DK9) has been chosen due to its near $1 \AA$ resolution and good percentile ranks. The structure also has co-crystallized ligand which can be used in the study of docking validation. The structure was downloaded from RCSB Protein Data Bank and prepared using the protein preparation wizard module because of was not suitable for immediate use in molecular modelling calculations [25]. The protein preparation workflow which detailed described in previous studies was incrementally introduced as a summary. (I) Bond order and charges have been assigned and then missing hydrogen atoms have been added to the structure. (II) Missing side chains have been filled. Amino acids have been ionized at physiological pH. (III) Water molecules have been removed. (IV) Energy minimization and geometry optimization have also been performed [26, 27].

\subsection{Binding sites prediction}

Binding sites of the prepared structure have been predicted using the SiteMap module of Mastro [28]. SiteScore and Dscore of the sites have been calculated using the default parameter of top-ranked potential protein binding site. Active site and druggable site properties of predicted binding sites have been determined by analyzing SiteScore and Dscore, respectively. The binding sites have also used at target selection and docking hits evaluation [29].

\subsection{Ligands preparation}

3D structures of the drugs have been downloaded from PubChem (https://pubchem.ncbi.nlm.nih.gov). A suitable structure for molecular docking studies of the drugs has been prepared using the LigPrep module [30]. Briefly, their correct molecular geometries and protonation state at $\mathrm{pH} 7.0 \pm 2.0$ have been prepared [31].

\subsection{Molecular docking studies}

In order to identify binding affinity and possible inhibition mechanism of the cephalosporin drugs have been carried out Glide docking and Induced-fit docking studies. Glide docking studies have been performed detection binding site where cephalosporin drugs are best fitted using Glide module of Maestro [32]. Validation of the Glide docking method has been performed with the re-docking procedure by extracting co-crystallized ligand in the structure before the drugs were docked into binding sites of the enzyme. Briefly, the grid box has been generated by selecting the predicted binding site using the Receptor Grid Generation module. Following grid generation, the cephalosporin drugs have been docked into all predicted binding site by setting Extra Precision (XP). After the docking process, XP scores have been evaluated for the detection of the best suitable binding site [33, 34].

After detection of the best suitable binding site, the drugs have been docked into the best suitable binding site for each drugs using induced-fit docking module 
of Maestro [35]. Validation of induced-fit docking method has been performed with the re-docking procedure by extracting co-crystallized ligand in the crystal structure of the enzyme before the drugs docked into their best suitable the binding site. Reliability of induced-fit docking method has been evaluated on the basis of RMSD value which calculated with Atom pair method in Superposition panel, between cocrystallized ligand and re-docked ligand. All drugs have been docked into their suitable binding site with the same procedures. For this purpose, the centroid of the residues has been generated around the predicted binding site in the binding site of the enzyme. After that, side chains have been automatically trimmed based on B-factor, closest residues to the ligand have been refined within $3.4 \AA$ of ligand pose in prime refinement. After the docking process, the binding affinity of the drugs has been determined by analyzing the Docking score and Emodel score [36].

\section{Results and Discussion}

GR is the key enzyme responsible for the maintenance of reduced glutathione in cells. Therefore, the enzyme plays a regulating role in glutathione related metabolism. Loss of the enzyme activity causes accumulation of toxic compound, oxidative stress and reduction of thiol moieties of proteins and low molecular weight compounds. So protection of the enzyme activity is very important. However, it has been reported that the hGR enzyme has been inhibited by some drugs and molecules such as cefotaxime, cefodizime [22], melatonin [37], imipenem, rifamycin, sulfanylacetamide, ceftazidime, chloramphenicol, ceftriaxon, vancomycin, cefuroxime, ornidazole [21], dantrolene [38], diclofenac sodium, ketoprofen, lornoxicam, tenoxicam etomidate, morphine, propofol [39], dacarbazine, thiocolchicoside, methotrexate, olanzapine, pantoprazole sodium, 5-fluorouracil [40], ketotifen, meloxicam, phenyramidol- $\mathrm{HCl}$, gadopentetic acid [17], cefuroxime, ceftriaxone, ceftizoxime and cefoperazone [24]. The enzyme kinetics experiments are very important clarifying inhibition type, $\mathrm{IC}_{50}$-value, and $\mathrm{Ki}$-value of molecules against their targets. However, these results may be inadequate explaining the binding mechanism between molecules and their targets in detail. In the previous studies, $\mathrm{IC}_{50}$-value and $\mathrm{Ki}$-value, as well as inhibition types of cephalosporins drugs against hGR enzyme, have been reported. In order to examine the possible inhibition mechanism of the drugs against their targets, we selected seven cephalosporins including cefoperazone, cefodizime, cefotaxime, ceftazidime, ceftizoxime, ceftriaxone and cefuroxime with potent inhibitory effect against hGR in vitro studies. Then, we have performed in silico evaluation of the drugs towards hGR.

In the beginning, we have predicted 5 different binding sites of the enzyme structure. The predicted sites have been illustrated in Figure 1. After that, in order to detect the best suitable binding site for the drugs, they have been docked into the predicted sites using Glide docking method. The best suitable binding sites for the drugs have been identified using their docking scores. The scores have been presented in Table 1. According to Docking scores, while Cefoperazone, Cefodizime, and Ceftazidime have located into the Sitel. Cefotaxime, Ceftriaxone, and Cefuroxime have located in the Site3. Ceftizoxime has located into the Site5, unlike other drugs. However, their possible inhibition mechanism has not evaluated with the Glide docking. Because the docking method uses searching for possible locations of the ligand in the binding sites of the receptor [41].

Table 1. The glide docking scores of the drugs into predicted binding sites of hGR enzyme

\begin{tabular}{|c|c|c|c|c|c|}
\hline \multirow{2}{*}{ Name } & \multicolumn{5}{|c|}{ XP Score (kcal/mol) } \\
\hline & Site 1 & Site 2 & Site 3 & Site 4 & Site 5 \\
\hline Cefoperazone & $-7.026^{*}$ & -1.911 & -4.857 & -2.727 & -6.122 \\
\hline Cefodizime & $-6.495^{*}$ & -3.843 & -4.955 & -3.019 & -5.894 \\
\hline Cefotaxime & -5.148 & -3.078 & $-5.391 *$ & -2.926 & -4.649 \\
\hline Ceftazidime & $-5.730^{*}$ & -2.169 & -4.723 & -5.105 & -5.186 \\
\hline Ceftizoxime & -4.390 & -1.346 & -3.643 & -2.913 & $-4.633^{*}$ \\
\hline Ceftriaxone & -4.668 & -2.707 & $-5.926^{*}$ & -3.122 & -5.046 \\
\hline Cefuroxime & -4.898 & -2.573 & $-5.213^{*}$ & -3.477 & -4.652 \\
\hline
\end{tabular}


Following detection of the best suitable binding sites for each drug, the drugs have docked into their binding site using the induced-fit docking method. Induced-fit docking method provides fully flexibility for protein structure by relaxing small backbone in the receptor structure as well as significant side-chain conformational changes [42], unlike the Glide docking method. Therefore, the method has been used for detecting of possible inhibition mechanism of the drugs.

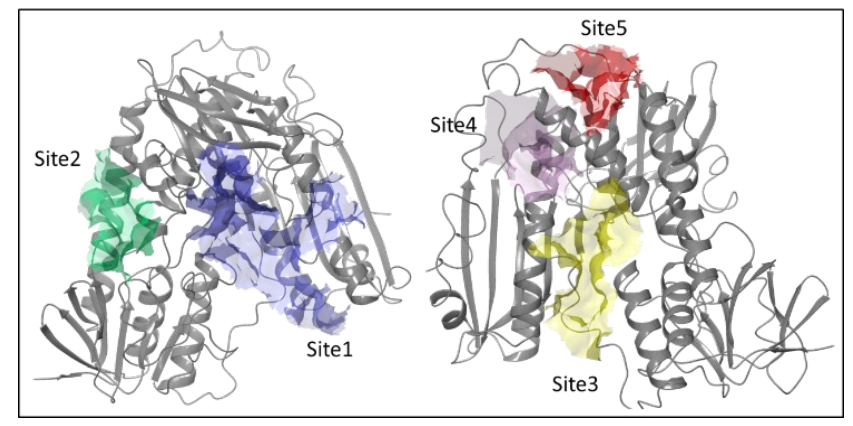

The human glutathione reductase is a flavoenzyme which uses flavin adenine dinucleotide (FAD) as a prostatic group in catalysis [43]. When NADPH binds to the enzyme, FAD acts as a bridge which transferred electron to Cys58-Cys63 disulfide bond from NADPH [44]. Reduced Cys58 residue causes two GSH molecules by attacking GSSG [43]. Therefore, after best suitable binding sites detection, the drugs have been docked into their best suitable binding sites using the induced-fit docking method. Fallowing docking procedure, docking hits for each drug have been evaluated on the bases of Docking scores. The scores have been presented in Table 2. Pose with the highest score in the negative direction has been chosen as the best-pose. Then, in order to detect possible inhibition mechanism of the drugs, their $2 \mathrm{D}$ interaction modes and 3D detailed binding modes have examined. Interacted residues with them have been presented in Table 3.

Figure 1. Predicted binding sites of the hGR enzyme.

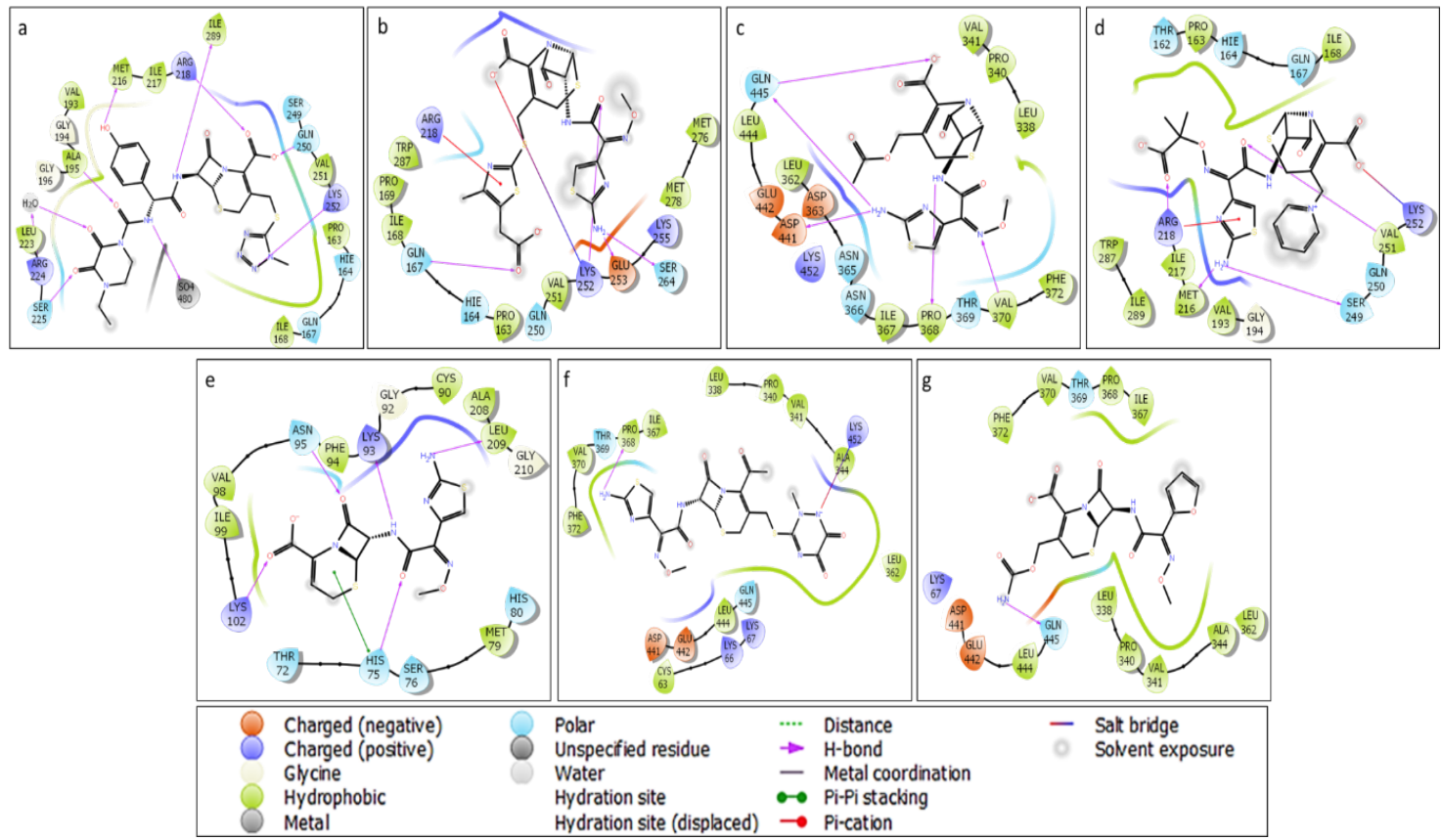

Figure 2. 2D interaction mode of best-posed drugs. (a) Cefoperazone, (b) Cefodizime, (c) Cefotaxime, (d) Ceftazidime, (e) Ceftizoxime, (f) Ceftriaxone and (g) Cefuroxime into their best suitable binding site.

The drugs have strong binding affinity due to the construction of a good few hydrogen bonds and aromatic hydrogen bonds as seen in Figure 2 and Figure 3. Cefoperazone, Cefodizime, and Ceftazidime interacted with Sitel residues have constituted more hydrogen bonds with the residues than those of other drugs. $\pi$ - $\pi$ Stacking, $\pi$-cation or salt bridge interaction have also contributed to the binding affinity of
Cefodizime, Ceftazidime, Ceftizoxime, and Ceftriaxone. The drugs fitted into Site1 and Site 3 have similar interaction with those of NADPH and FAD because the site has constituted parts of catalytic active sites. 2D interactions of NADPH and FAD have been shown in Figure 5. Nordhoff et. al. [45] have expressed that 436-459 residues responsible for dimerization of hGR enzyme monomers. Site3 residues have included some of the 436-459 residues. 
Table 2. Induced fit docking scores of the drugs into their best binding site.

\begin{tabular}{|c|c|c|c|c|}
\hline Name & Structure & $\begin{array}{c}\text { IFD Docking Score } \\
(\mathrm{kcal} / \mathrm{mol})\end{array}$ & $\begin{array}{c}\text { Experimental } \mathrm{K}_{\mathrm{i}} \\
(\mathrm{mM})\end{array}$ & Inhibition Type \\
\hline Cefaperazone & & -10.643 & $\begin{array}{c}0.029 \\
{[24]}\end{array}$ & Non-Competitive \\
\hline Cefodizime & & -6.120 & $\begin{array}{c}0.745 \pm 0.222 \\
{[22]}\end{array}$ & Competitive \\
\hline Cefotaxime & & -8.035 & $6.512 \pm 4.114[22]$ & Non-Competitive \\
\hline Ceftazidime & & -6.480 & $\begin{array}{c}3.590 \pm 0.510 \\
{[21]}\end{array}$ & Competitive \\
\hline Ceftizoxime & & -7.852 & $\begin{array}{c}22.760 \\
{[24]}\end{array}$ & Non-Competitive \\
\hline Ceftriaxone & & -6.079 & $\begin{array}{c}3.710 \pm 0.600 \\
{[24]}\end{array}$ & Non-Competitive \\
\hline Cefuroxime & & -7.690 & $\begin{array}{c}23.500 \pm 2.940[21, \\
24]\end{array}$ & Competitive \\
\hline
\end{tabular}

Cefotaxime, Ceftriaxone, and Cefuroxime have formed hydrogen bond, salt bridge, and negative interactions with the dimerization residues as seen in Figure 2-c-f-g. Therefore, they can cause inhibition of the enzyme by hindering dimerization. Unlike the others, Ceftizoxime has interacted with residues of the different binding site, site5, as seen in Figure 2-e and 3-e. The site has named as aromate binding site by
Kasozi et. al. [46]. They have identified that pyocyanin molecule inhibited the hGR enzyme by interacting with the residues of the aromate binding site. According to the docking scores and the interaction modes of the drugs, we have explored that they exhibit strong binding affinity and are potent inhibitor for hGR as indicated previously in vitro studies. 


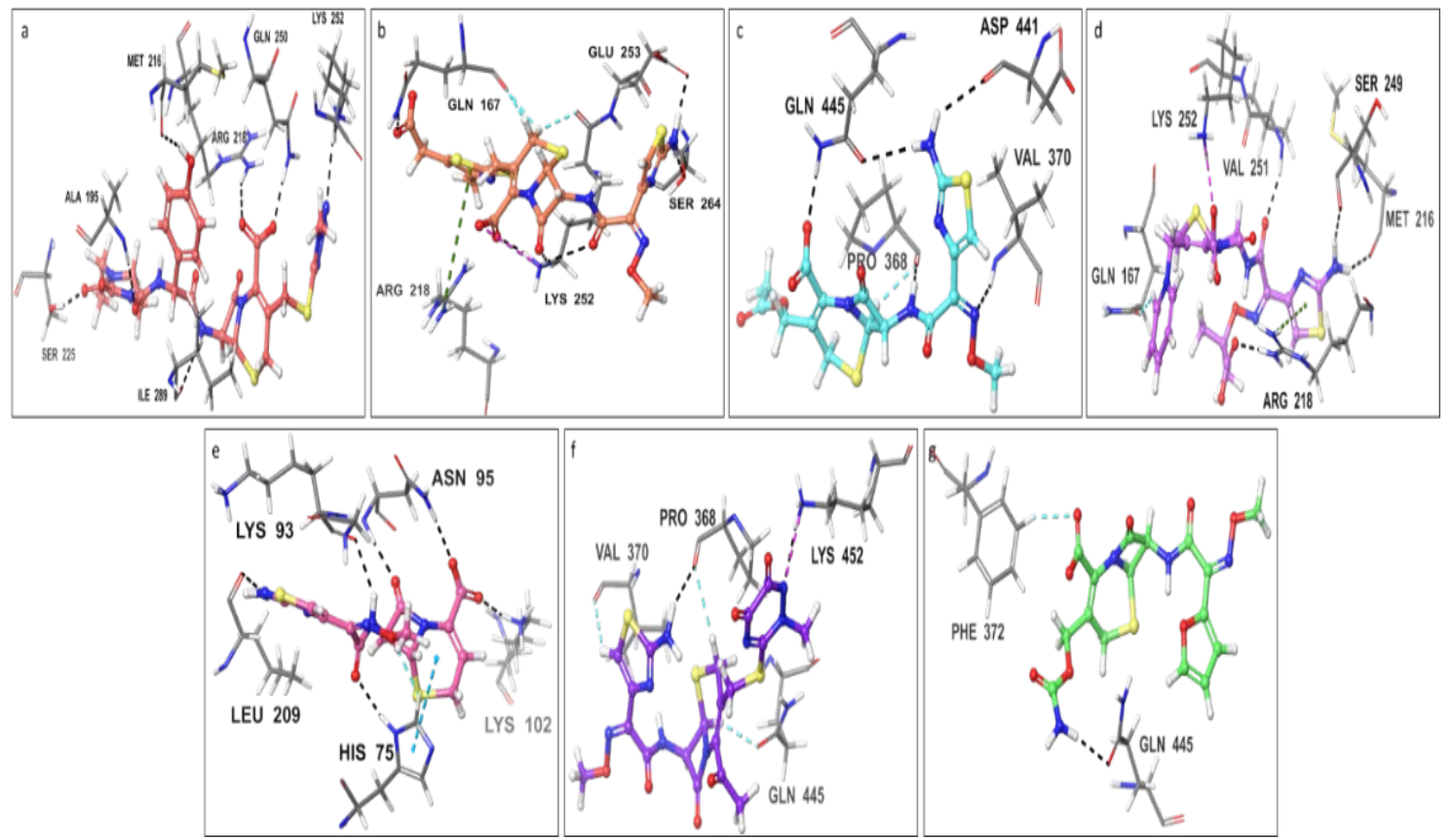

Figure 3. 3D detailed binding mode of best-posed drugs. (a) Cefoperazone, (b) Cefodizime, (c) Cefotaxime, (d) Ceftazidime, (e) Ceftizoxime, (f) Ceftriaxone and (g) Cefuroxime into their best suitable binding site. Drugs have been represented as colored ball-stick model and amino acid residues have been represented as grey thick-tube model.

Table 3. Interacted residues with the drugs into hGR enzyme.

\begin{tabular}{lccc}
\hline Name & Hydrogen Bond & $\begin{array}{c}\pi \text { - } \pi \text { Stacking } \\
\text { and } \pi \text {-cation }\end{array}$ & Salt Bridge \\
\hline Cefaperazone & Ala195, Met216, Arg218, Ser225, Gln250, Lys252, Ile289 & - & - \\
Cefodizime & Gln167, ,ye252, Glu253, Ser264 & Arg218 & Lys252 \\
Cefotaxime & Pro368, Val370, Asp441, Gln445 & - & - \\
Ceftazidime & Gln167, Met216, Arg218, Ser249, Val251, Lys252 & Arg218 & - \\
Ceftizoxime & His75, Lys93, Asn95, Lys102, Leu209 & His75 & Lys452 \\
Ceftriaxone & Pro368, Val370, Gln445, Lys452 & - & - \\
Cefuroxime & Phe372, Gln445 & - & - \\
\hline
\end{tabular}

In order to give a more detailed explanation for their possible inhibition mechanism, we also compared confirmation of important catalytic active site residue

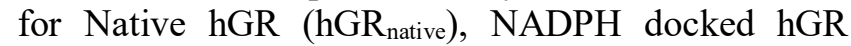
(hGR NADPH$)$ and Cefoperazone docked hGR

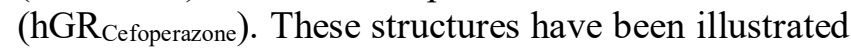
in Figure 4. For the comparison, we have used Cys58, Cys63, Tyr197, and Phe327 residues. Because Cys58 and Cys63 residues directly participate in the catalytic activity of the enzyme and conformations of Tyr197 and Phe327 residues have changed with NADPH binding [43]. According to Figure 4, the position of
hGR $_{\text {NADPH }}$ Cys58 and Cys63 residues significantly differ from those of $\mathrm{hGR}_{\text {native }}$ end $\mathrm{hGR}_{\text {Cefoperazone }}$ and the distance between the residues has calculated as 0.646 $\AA$. These results have indicated that NADPH bonded structure get active form. Alongside the residues, the position of Tyr197 and Phe327 residues of hGR $_{\text {Cefoperazone }}$ differ from hGR $_{\mathrm{NADPH}}$ structure and the distance between the residues has calculated as 0.322 $\AA$. The results have also indicated that Cefoperazone causes to remain at the inactive form of the enzyme by effecting conformation of the catalytic active site. 


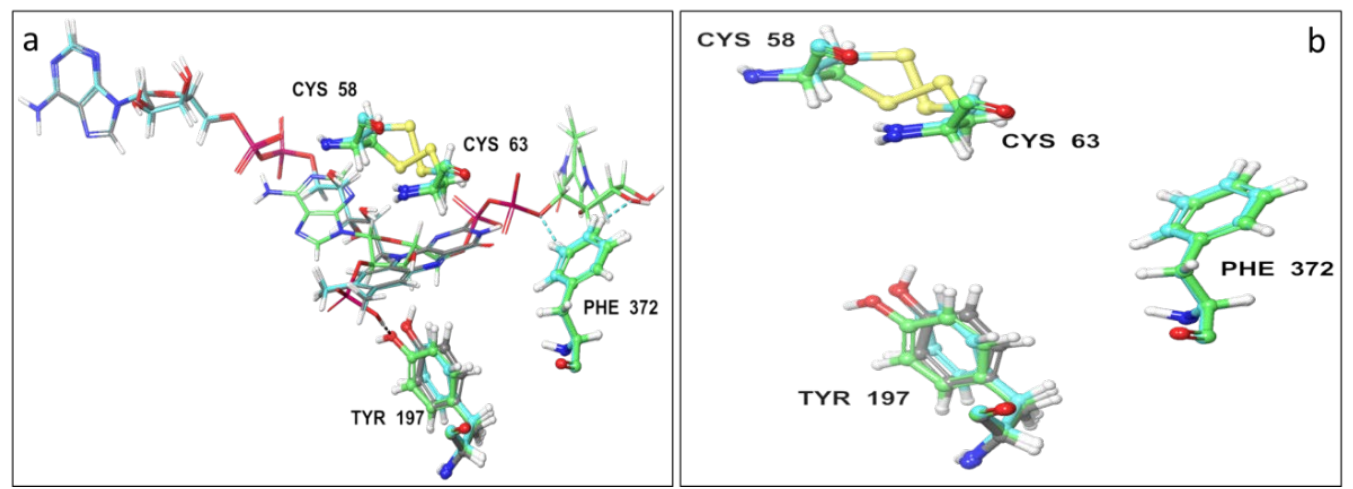

Figure 4. Conformation of active site residues. (a) FAD and residues and (b) active site residues. FAD and residues of

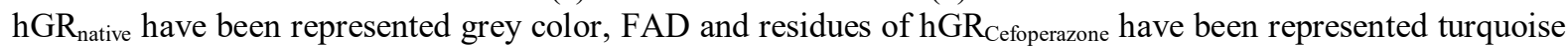
color, and residues of $\mathrm{hGR}_{\mathrm{NADPH}}$ has been represented green color.
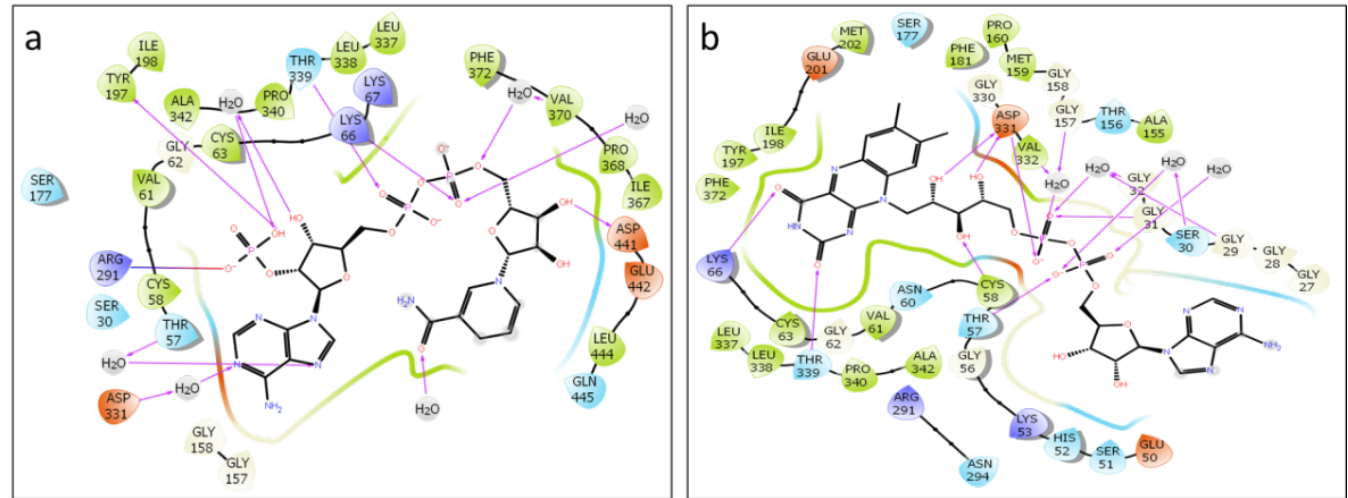

Figure 5. 2D interaction mode of the best-posed (a) NADPH and (b)FAD into catalytic active site of hGR enzyme.

\section{Conclusions}

In this study, we determined theoretically for the first time that the certain seven cephalosporins have an inhibitory effect against human glutathione reductase. Molecular docking results have shown that the drugs have exhibited potent inhibition compatible with previously reported in vitro experiments. The results have also shown that the drugs inhibit the enzyme with different mechanisms including structural conformational changing into the catalytic active site and hindering dimerization. Thus, our findings provide new insights into the potential inhibition mechanism of these inhibitors of hGR enzyme. The present study gives us a new perspective for understanding how cephalosporins inhibit the hGR enzyme. These results would be helpful for designing new inhibitors and understanding of potential inhibition mechanism of the other known inhibitors.

\section{Acknowledgments}

The author is grateful to Dr. Halide Sedef Karaman for giving her technical guidance while processing docking study of this article and for supporting small drug discovery suite software.

\section{Conflicts of interest}

The authors state that did not have a conflict of interests

\section{References}

[1] Johnson A.E., Antibiotics, Am. J. Nurs., 50(11) (1950) 688-690.

[2] McManus M.C., Mechanisms of bacterial resistance to antimicrobial agents, Am J Health Syst Pharm, 54(12) (1997) 1420-1433; quiz 14441426.

[3] Hancock R.E., Peptide antibiotics, Lancet, 349(9049) (1997) 418-422.

[4] Poehlsgaard J., Douthwaite S., The bacterial ribosome as a target for antibiotics, Nature Reviews Microbiology, 3(11) (2005) 870-881.

[5] Spratt B.G., Resistance to antibiotics mediated by target alterations, Science, 264(5157) (1994) 388393.

[6] Maxwell A., DNA gyrase as a drug target, Trends in Microbiology, 5(3) (1997) 102-109. 
[7] Ahmad S.I., Kirk S.H., Eisenstark A., Thymine metabolism and thymineless death in prokaryotes and eukaryotes, Annual Review of Microbiology, 52 (1998) 591-625.

[8] Berdy J., Recent developments of antibiotic research and classification of antibiotics according to chemical structure, Adv Appl Microbiol, 18(0) (1974) 309-406.

[9] Maddison J.E., Watson A.D.J., Elliott J., Antibacterial drugs. In small animal climical pharmacology, 2nd ed. Philadelphia: Elsevier, 2008 ; $145-185$.

[10] Farrington M., Antibacterial drugs. Clinical Pharmacology, 11th ed. London: Elsevier, 2012; 173-190.

[11] Watkins R. R., Bonomo R. A., $\beta$ - Lactam antibiotics Anti-infective therapy, 4th ed. Amsterdam: Elsevier, 2017;1203-1216.e2.

[12] Moellering R.C., Swartz M.N., Drug therapy: the newer cephalosporins, N. Engl. J. Med., 294 (1976) 24-28.

[13] Mehta D., Sharma A.K., Cephalosporins: A review on imperative class of antibiotics, Molecular Pharmacology, 2016 (1) (2015) 1-6.

[14] Hughes D. L., Patent review of manufacturing routes to fifth-generation cephalosporin drugs. Part 1, Ceftolozane. Organic Process Research \& Development, 21(3) (2017) 430-443.

[15] Deleve L.D., Kaplowitz N., Importance and regulation of hepatic glutathione, Seminars in Liver Disease, 10(4) (1990) 251-266.

[16] Anderson M.E., Glutathione: an overview of biosynthesis and modulation, Chemico-Biological Interactions, 112 (1998) 1-14.

[17] Karaman M., Akkemik E., Budak H. and Ciftci M., In vitro effects of some drugs on human erythrocyte glutathione reductase, Journal of Enzyme Inhibition and Medicinal Chemistry, 27(1) (2012) 18-23.

[18] Meister A., Anderson M.E., Glutathione, Annu Rev Biochem, 52 (1983) 711-760.

[19] Lii C.K., Chai Y.C., Zhao W., Thomas J.A. and Hendrich S., S-Thiolation and irreversible oxidation of sulfhydryls on carbonic-anhydraseiii during oxidative stress - a method for studying protein modification in intact-cells and tissues, Archives of Biochemistry and Biophysics, 308(1) (1994) 231-239.
[20] Schirmer R.H., Krauth-Siegel R.L., Schulz G.E., Coenzymes and cofactors, New York: Vol. 3: John Wiley and Sons, 1989; 553-559.

[21] Senturk M., Kufrevioglu O.I. , Ciftci M., Effects of some antibiotics on human erythrocyte glutathione reductase: an in vitro study, Journal of Enzyme Inhibition and Medicinal Chemistry, 23(1) (2008) 144-148.

[22] Erat M., Sakiroglu H., Ciftci M., Effects of some antibiotics on glutathione reductase activities from human erythrocytes in vitro and from rat erythrocytes in vivo, Journal of Enzyme Inhibition and Medicinal Chemistry, 20 (1) (2005) 69-74.

[23] Dershwitz M., Novak R.F., Lack of inhibition of glutathione-reductase by un-nitrated derivatives of nitrofurantoin, Biochemical and Biophysical Research Communications, 92(4) (1980) 13131319.

[24] Ekinci D., Cankaya M., Gul I. and Coban T.A., Susceptibility of cord blood antioxidant enzymes glutathione reductase, glutathione peroxidase and glutathione S-transferase to different antibiotics: in vitro approach, $J$ Enzyme Inhib Med Chem., 28(4) (2013) 824-829.

[25] Protein Preparation Wizard; Epik, Schrödinger, LLC, New York, NY, 2016; Impact, Schrödinger, LLC, New York, NY, 2016; Prime, Schrödinger, LLC, New York, NY, 2019.

[26] Kalin R., Koksal Z., Kalin P., Karaman M., Gulcin I. and Ozdemir, H. In vitro effects of standard antioxidants on lactoperoxidase enzymeA molecular docking approach, $J$ Biochem. Mol. Toxicol. (2019) e22421.

[27] Bayrak, C., Taslimi, P., Karaman, H. S., Gulcin, I. and Menzek A., The first synthesis, carbonic anhydrase inhibition and anticholinergic activities of some bromophenol derivatives with $\mathrm{S}$ including natural products, Bioorg Chem., 85 (2019) 128-139.

[28] SiteMap, Schrödinger, LLC, New York: NY. (2019).

[29] Bal S., Kaya R., Gok Y., Taslimi P., Aktas A., Karaman M. and Gulcin I., Novel 2methylimidazolium salts: Synthesis, characterization, molecular docking, and carbonic anhydrase and acetylcholinesterase inhibitory properties, Bioorg Chem. (2019) 103468.

[30] LigPrep, Schrödinger, LLC, New York: NY. (2019). 
[31] Taslimi P., Turkan F., Cetin A., Burhan H., Karaman M., Bildirici I., Gulcin I. and Sen F., Pyrazole[3,4-d]pyridazine derivatives: Molecular docking and explore of acetylcholinesterase and carbonic anhydrase enzymes inhibitors as anticholinergics potentials, Bioorg Chem, 92 (2019) 103213.

[32] Glide, Schrödinger, LLC, New York, NY (2019).

[33] Yigit B., Kaya R., Taslimi P., Isik Y., Karaman M., Yigit M., Ozdemir I. and Gulcin I. Imidazolinium chloride salts bearing wingtip groups: Synthesis, molecular docking and metabolic enzymes inhibition, J Mol Struct, 1179 (2019) 709-718.

[34] Turkan F., Cetin A., Taslimi P., Karaman H. S. and Gulcin I., Synthesis, characterization, molecular docking and biological activities of novel pyrazoline derivatives, Arch Pharm (Weinheim), 352(6) (2019) e1800359.

[35] Induced Fit Docking protocol; Glide, Schrödinger, LLC, New York, NY, 2016; Prime, Schrödinger, LLC, New York, NY. (2019).

[36] Bayindir S., Caglayan C., Karaman M. and Gulcin I., The green synthesis and molecular docking of novel $\mathrm{N}$-substituted rhodanines as effective inhibitors for carbonic anhydrase and acetylcholinesterase enzymes, Bioorg Chem, 90 (2019) 103096.

[37] Erat M., Ciftci M., Effect of melatonin on enzyme activities of glutathione reductase from human erythrocytes in vitro and from rat erythrocytes in vivo, Eur J Pharmacol, 537(1-3) (2006) 59-63.

[38] Senturk M., Gulcin I., Ciftci M. and Kufrevioglu O.I., Dantrolene inhibits human erythrocyte glutathione reductase, Biological \& Pharmaceutical Bulletin, 31(11) (2008) 20362039.

[39] Senturk M., Kufrevioglu O.I. and Ciftci M., Effects of some analgesic anaesthetic drugs on human erythrocyte glutathione reductase: an in vitro study, $J$ Enzyme Inhib Med Chem, 24(2) (2009) 420-424.

[40] Akkemik E., Senturk M., Ozgeris F.B., Taser P., Ciftci M., In vitro eff ects of some drugs on human erythrocyte glutathione reductase, Turk J Med Sci, 42(2) (2011) 235-241.

[41] Friesner R.A., Banks J.L., Murphy R.B., Halgren T.A., Klicic J.J., Mainz D.T., Repasky M.P., Knoll E.H., Shelley M., Perry J.K., Shaw D.E.,
Francis P. and Shenkin P.S., Glide: a new approach for rapid, accurate docking and scoring. 1. Method and assessment of docking accuracy, $J$ Med Chem, 47(7) (2004) 1739-1749.

[42] Sherman W., Beard H.S. and Farid R., Use of an induced fit receptor structure in virtual screening, Chem Biol Drug Des, 67(1) (2006) 83-84.

[43] Berkholz D.S., Faber H.R., Savvides S.N. and Karplus P.A., Catalytic cycle of human glutathione reductase near $1 \mathrm{~A}$ resolution, $J \mathrm{Mol}$ Biol, 382(2) (2008) 371-384.

[44] Sustmann R., Sicking W., Schulz G.E., The Active Site of Glutathione Reductase: An Example of Near Transition-State Structures. Angew., Chem. Int. Ed. Eng., 28 (1989) 10231025.

[45] Nordhoff A., Tziatzios C., Van den Broek J. A., Schott M.K., Kalbitzer H.R., Becker K., Schubert D. and Schirmer R.H., Denaturation and reactivation of dimeric human glutathione reductase--an assay for folding inhibitors, Eur $J$ Biochem, 245(2) (1997) 273-282.

[46] Kasozi D.M., Gromer S., Adler H., Zocher K., Rahlfs S., Wittlin S., Fritz-Wolf K., Schirmer R.H. and Becker K., The bacterial redox signaller pyocyanin as an antiplasmodial agent: comparisons with its thioanalog methylene blue, Redox Rep, 16(4) (2011) 154-165. 